\title{
A Sensitive and Selective Ratiometric Near IR Fluorescent Probe for Zinc lons Based on the Distyryl-Bodipy Fluorophore
}

2008

Vol. 10, No. 18 $4065-4067$

\section{Serdar Atilgan, ${ }^{, \neq \ddagger}$ Tugba Ozdemir, ${ }^{\dagger}$ and Engin U. Akkaya ${ }^{*, \S}$}

Department of Chemistry, Middle East Technical University, Ankara, Turkey TR-06531,

Department of Chemistry, Suleyman Demirel University, Isparta, Turkey TR-32260,

and Department of Chemistry and UNAM-Institute of Materials Science and

Nanotechnology, Bilkent University, Ankara, Turkey, TR-06800

eua@fen.bilkent.edu.tr

Received July 9, 2008

\section{ABSTRACT}

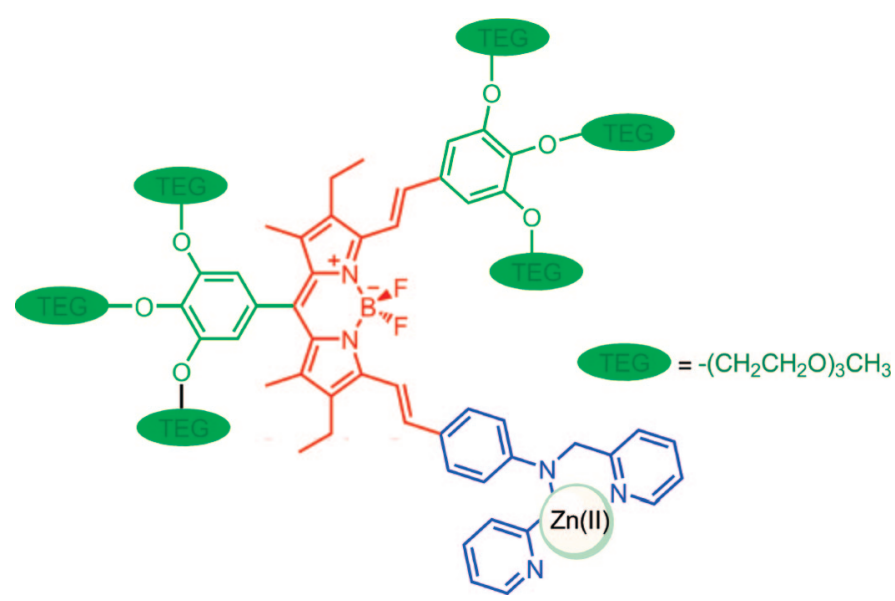

A novel distyryl-substituted boradiazaindacene (bodipy) dye with an emission peak moving hypsochromically from $730 \mathrm{to} 680 \mathrm{~nm}$ on $\mathrm{Zn}$ (II) ion binding seems to be promising as one of the very few water-soluble fluorescent chemosensors emitting in the near IR region.

The design of fluorescent chemosensors for ions implicated in important biological processes, especially linked to human disease states, is an active research area. Zinc(II) ions are involved in the biology of Alzheimer's disease ${ }^{1}$ and diabetes, ${ }^{2}$ among others. ${ }^{3}$ It is now well established that large amounts of "free" zinc are sequestered in the secretory granules of different types of mammalian cells, and its release

\footnotetext{
${ }^{\dagger}$ Middle East Technical University.

\$ Suleyman Demirel University.

$\S$ Bilkent University.

(1) Noy, D.; Solomonov, I.; Sinkevich, O.; Arad, T.; Kjaer, K.; Sagi, I. J. Am. Chem. Soc. 2008, 130, 1376-1383.
}

is under the precise control of secretagogues. ${ }^{4}$ For fluorescent chemosensors aimed at cellular imaging or real-time visualization of ion concentrations, additional constraints would apply. Long wavelength excitability and emission are very important for reduced scattering and securing low back-

(2) Taylor, C. G. Biometals 2005, 18, 305-312.

(3) (a) Frassinetti, S.; Bronzetti, G.; Caltavuturo, L.; Cini, M.; Croce, C. D. J. Environ. Pathol. Toxicol. Oncol. 2006, 25, 597610. (b) Lim, C. L.; Freake, H. D.; Brückner, C. Chem.-Eur. J. 2005, 11, 38-39.

(4) (a) Morita, Y.; Sawada, M.; Seno, H.; Takaishi, S.; Fukuzawa, H.; Miyake, N.; Hiai, H.; Chiba, T. Biochim. Biophys. Acta 2001, 1540, 4349. (b) Frederickson, C. J.; Perez-Clausell, J.; Danscher, G. J. Histochem. Cytochem. 1987, 35, 579-583. 
ground emissions. In addition, signal transduction in the wavelength ratiometric mode is highly advantageous.

In recent literature, a large number of fluorescent probes for zinc have been proposed based on different fluorophores such as quinoline, ${ }^{5}$ boradiazaindacene (bodipy), ${ }^{6}$ dansyl, ${ }^{7}$ fluorescein, ${ }^{8}$ anthracene, ${ }^{9}$ acridine, ${ }^{10}$ benzofuran, ${ }^{11}$ naphthalimide, ${ }^{12}$ cyanine, ${ }^{13}$ and squaraines. ${ }^{14}$

Unfortunately, for most of them, water solubility is limited, thus various solvent mixtures are used in characterization. This fact, together with the requirement for shorter wavelength excitation, hinders biological applications.

As part of our ongoing interest in rational design of ratiometric fluorescent chemosensors, emitting especially in the red end of the visible spectrum, we are particularly intrigued by the distyryl-bodipy ${ }^{15}$ dyes. These novel derivatives of wellknown bodipy dyes are emerging as promising red emitting dyes with interesting applications as sensitizers for photodynamic therapy ${ }^{15 a}$ and ion sensing. ${ }^{15 b}$ The distyryl-bodipy dyes can be synthesized with water solubilizing groups, which increases the likelihood of biological applications. When the styryl groups carry dialkylamino groups, the ICT process can be modulated by cation binding which provides ample opportunities of cation sensing. ${ }^{16}$

With these considerations, we set out to synthesize compound 4 (Scheme 1). The synthesis requires stepwise Knoevenagel condensations with two different aldehydes to yield the distyrl-bodipy. The TEG (triethyleneglycol) groups are placed on a gallic acid derived, 3,4,5-trihydroxyphenyl unit. The metal chelator is a well-known $\mathrm{Zn}$ (II) specific ligand, dipicolylamine (DPA). The target compound $\mathbf{4}$ was obtained in satisfactory yield and characterized by ${ }^{1} \mathrm{H}$ and ${ }^{13} \mathrm{C}$ NMR and HRMS. Six TEG groups are clearly enough to make this molecule compatible with water, and the spectral

(5) (a) Fahrni, C. J.; O'Halloran, T. V. J. Am. Chem. Soc. 1999, 121, 11448-11458. (b) Zhang, Y.; Guo, X.; Si, W.; Jia, L.; Qian, X. Org. Lett. 2008, 10, 473-476.

(6) (a) Turfan, B.; Akkaya, E. U. Org. Lett. 2002, 4, 2857-2859. (b) Harriman, A.; Mallon, L. J.; Stewart, B.; Ulrich, G.; Ziessel, R. Eur. J. Org. Chem. 2007, 3191-3198.

(7) Jiang, P.; Chen, L.; Lin, J.; Liu, Q.; Ding, J.; Gao, X.; Guo, Z. Chem. Commun. 2002, 1424-1425.

(8) Sun, W. C.; Gee, K. R.; Klaubert, D. H.; Haugland, R. P. J. Org. Chem. 1997, 62, 6469-6475.

(9) (a) Ojida, A.; Mito-Oka, Y.; Inoue, M.; Hamachi, I. J. Am. Chem. Soc. 2002, 124, 6256-6258. (b) Ertas, N.; Akkaya, E. U.; Ataman, O. Y Talanta 2001, 51, 693-699.

(10) Park, M. S.; Swamy, K. M. K.; Lee, Y. J.; Lee, H. N.; Jang, Y. J.; Moon, Y. H.; Yoon, J. Tetrahedron Lett. 2006, 47, 8129-8132.

(11) Maruyama, S.; Kikuchi, K.; Hirano, T.; Urano, Y.; Nagano, T. J. Am. Chem. Soc. 2002, 124, 10650-10651.

(12) (a) Xu, Z.; Qian, X.; Cui, J.; Zhang, R. Tetrahedron 2006, 62, 10117. (b) Lee, T. C.; Parkesh, R. Org. Biomol. Chem. 2003, 1, 32653267. (c) Parkesh, R.; Lee, T. C.; Gunnlaugsson, T. Org. Biomol. Chem. 2007, 5, 310-317.

(13) Kiyose, K.; Kojima, H.; Urano, Y.; Nagano, T. J. Am. Chem. Soc. 2006, 128, 6548-6549.

(14) (a) Dilek, G.; Akkaya, E. U. Tetrahedron Lett. 2000, 41, 37213724. (b) Carol, P.; Sreejith, S.; Ajayaghosh, A. Chem. Asian J. 2007, 2, 338-348.

(15) (a) Dost, Z.; Atilgan, S.; Akkaya, E. U. Tetrahedron 2006, 62, 84848488. (b) Atilgan, S.; Ekmekci, Z.; Dogan, A. L.; Guc, D.; Akkaya, E. U. Chem. Commun. 2006, 4398-4400.

(16) (a) Coskun, A.; Akkaya, E. U. J. Am. Chem. Soc. 2005, 127, 1046410465. (b) Coskun, A.; Akkaya, E. U. J. Am. Chem. Soc. 2006, 128, 14474 14475. (c) Peng, X.; Du, J.; Fan, J.; Wang, J.; Wu, Y.; Zhao, J.; Sun, S.; Xu, T. J. Am. Chem. Soc. 2007, 129, 1500-1501.
Scheme 1. Synthesis of the Near IR Emitting, Water-Soluble DS-Bodipy-Based Chemosensor 4<smiles>CCOc1cc(C2=C(C)C(C)=C(CC)[P+]2(F)[P+](C)(F)F)c(C)c(C)c1CC</smiles><smiles>CCOc1cc(CC(C)C)cc(OC)c1OCCOC</smiles><smiles>CCOc1cccc(OCC)c1OCCOC</smiles>

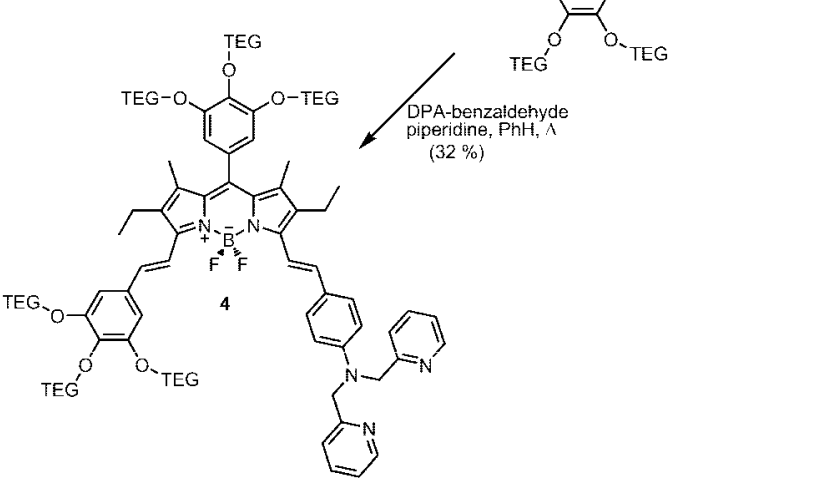

data to be discussed from this point on are obtained in 5:95 ethanol-aqueous buffer solutions.

The absorption spectrum (Supporting Information) displays a broad peak centered at $680 \mathrm{~nm}$, and the molar extinction coefficient is $72000 \mathrm{M}^{-1} \mathrm{~cm}^{-1}$ at this wavelength. The emission spectrum obtained in aqueous buffer solution $(5 \%$ ethanol was added as a cosolvent) shows a peak centered at $726 \mathrm{~nm}$ (Figure 1). Gradual addition of $\mathrm{Zn}$ (II) ions to this

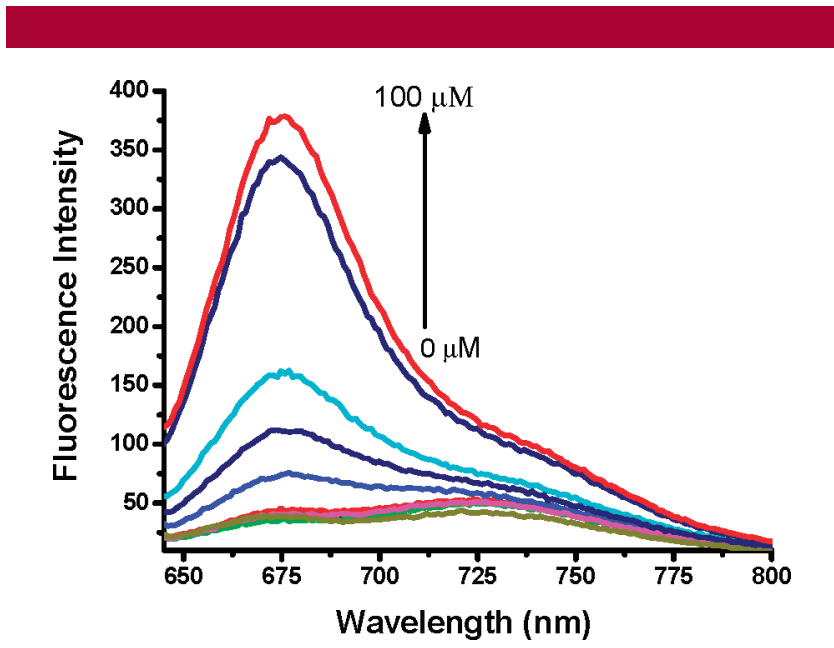

Figure 1. Change in the emission spectrum of the chemosensor 4 $(2.5 \mu \mathrm{M})$ in response to increasing concentrations of $\mathrm{Zn}$ (II) in an ethanol-aqueous buffer mixture (5\% in ethanol, HEPES $0.1 \mathrm{M}$, $\mathrm{pH}=7.2$ ). Zinc concentrations were varied in the following order: $0,0.25,0.5,1,2,5,10,20,50,100 \mu \mathrm{M}$. Excitation was at $630 \mathrm{~nm}$, with slit widths of $5 \mathrm{~nm}$.

solution results in a blue shift to $625 \mathrm{~nm}$ with a concomitant increase in emission intensity. This clearly shows that the 
coordination of $\mathrm{Zn}(\mathrm{II})$ ions effectively blocks excited-state charge transfer from the dipicolylphenyl group. Hill plot analysis of the data obtained in the titration of $\mathbf{4}$ with $\mathrm{Zn}$ (II) yielded a 1:1 stoichiometry (slope $=0.97$ ) with a dissociation constant $\left(K_{\mathrm{d}}\right)$ of $2.0 \times 10^{-5} \mathrm{M}$. The fluorescence emission of the $\mathrm{Zn}(\mathrm{II})$ complex is bright red, whereas weaker intensity emission of the free chemosensor is hardly visible since it is at the red end of the visible spectrum, extending to near IR. Not surprisingly, the dipicolylamine ligand imparts remarkable metal ion selectivity onto this chemosensor (Figure 2). The chemosensor 4 generates the largest signal

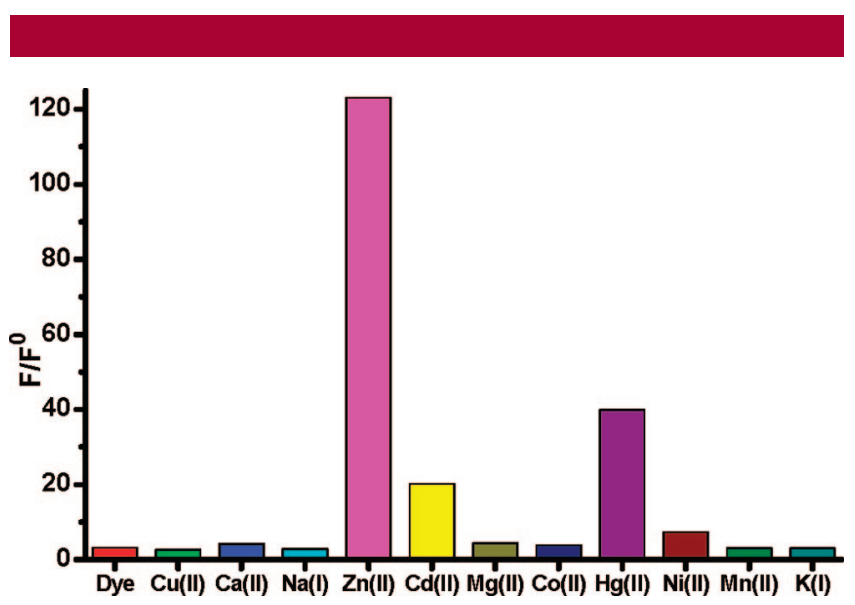

Figure 2. Normalized emission intensities at $680 \mathrm{~nm}$ (the emission intensity of the free dye $=1)$ of the chemosensor $(1.2 \mu \mathrm{M})$ in the presence of selected metal ions $(1.0 \mathrm{mM})$. Excitation was done at $630 \mathrm{~nm}$ with $5 \mathrm{~nm}$ slit widths. Solvent: ethanol-aqueous buffer mixture (5\% in ethanol, HEPES $0.1 \mathrm{M}, \mathrm{pH}=7.2)$.

in the presence of $\mathrm{Zn}(\mathrm{II})$ ions, but $\mathrm{Hg}(\mathrm{II})$ and $\mathrm{Cd}(\mathrm{II})$ also show some response. Fortunately, in biological media (unlike environmental samples), these three ions rarely compete, and our data show that most likely biological interferants such as $\mathrm{Ca}(\mathrm{II}), \mathrm{K}(\mathrm{I}), \mathrm{Na}(\mathrm{I})$, and $\mathrm{Mg}(\mathrm{II})$ have no effect on the emission spectrum. The results of a competition experiment between $\mathrm{Zn}(\mathrm{II})$ and selected metal ions is shown in Figure 3. Digital photographs (Figure 4) of the aqueous solutions of the chemosensor with added Zn(II) clearly show very large enhancement of the red emission under UV illumination at $360 \mathrm{~nm}$, with no perceivable changes in the presence of other biologically relavant ions.

In conclusion, we have demonstrated that versatile bodipy chemistry allows the synthesis of long wavelength emitting, water-soluble dyes through stepwise reaction of the methyl groups at the 3 and 5 positions of the bodipy core. Thus, multiple and distinct functional groups can easily be placed on the chromophore, offering many opportunities for the

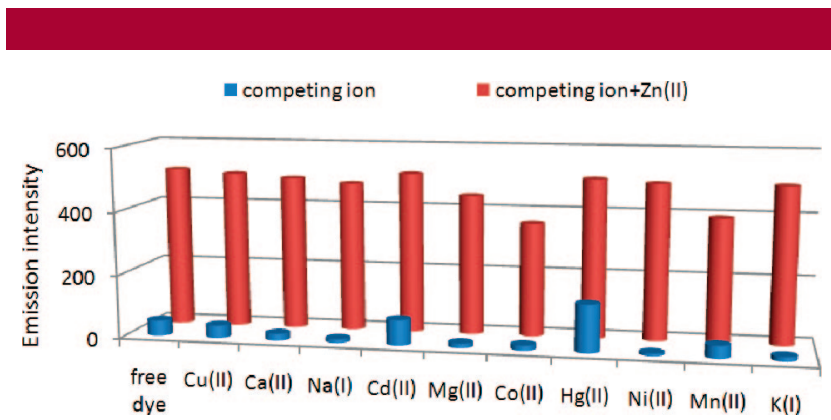

Figure 3. Results of the competition experiments between $\mathrm{Zn}$ (II) and selected metal ions. The free dye 4 (chemosensor) concentration was set at $5.0 \mu \mathrm{M}$. Excitation was at $630 \mathrm{~nm}$; emission intensity values at $680 \mathrm{~nm}$ were collected; and all metal ions were added at $200 \mu \mathrm{M}$ concentration. Solvent: ethanol-aqueous buffer mixture (5\% in ethanol, HEPES 0.1 M, pH = 7.2).

rational design for novel ratiometric chemosensors. The chemosensor discussed in this communication is a prototype

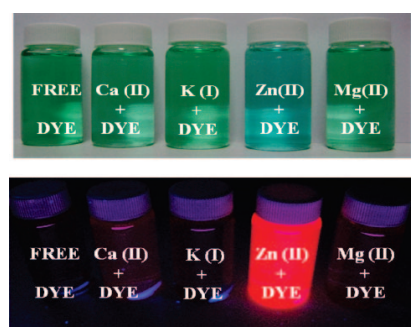

Figure 4. Digital photographs of the chemosensor solutions (5.0 $\mu \mathrm{M})$ in the presence of different metal ions at $100 \mu \mathrm{M}$ concentration. The upper plate is taken under ambient light, and the bottom one under UV illumination at $360 \mathrm{~nm}$. Solvent: ethanol-aqueous buffer mixture (5\% in ethanol, HEPES $0.1 \mathrm{M}, \mathrm{pH}=7.2$ ).

for such molecular ion sensors to be developed via this approach.

Acknowledgment. This work was supported by the Turkish Scientific and Technical Research Council (TUBITAK) and the Turkish Academy of Sciences (TUBA). The authors gratefully acknowledge Mr. Ilker Kutuk (METU) for his assistance with the synthesis work.

Supporting Information Available: Syntheses, experimental details, and additional spectroscopic data for all new compounds. This material is available free of charge via the Internet at http://pubs.acs.org.

OL801554T 